\title{
Failed fibre optic intubation in a difficult airway- an anaesthetic nightmare
}

\author{
Anita Kulkarni', Soumi Pathak ${ }^{2 *}$ \\ Senior Consultant Anaesthetist ${ }^{1}$, Fellow in Oncoanaesthesia ${ }^{2 *}$, Rajiv Gandhi Cancer Institute and \\ Research Centre, Delhi, India.
}

\begin{abstract}
Awake fibreoptic intubation is the gold standard for an anticipated difficult airway, but it can fail even in expert hands. Supraglottic devices cannot be used in cases of oral masses or in large masses of the neck with distorted glottis. Thus, one should have alternative plans for securing the airway without causing hypoxia and the decision to perform tracheostomy must be taken at the right time.
\end{abstract}

Keywords: Difficult airway; fibreoptic; Mc Coy; video laryngoscope

\section{Introduction}

Fibreoptic intubation is extremely difficult in a distorted airway, or when fibre scope views are obscured, by massive haematemesis or excessive sputum. We report two cases of failed fibreoptic intubation where McCoy laryngoscope and $\mathrm{C}$ Mac D blade was used as rescue devices for intubating the trachea.

\section{Case 1}

A 77-year-old, 66kg female, diagnosed with carcinoma right breast was planned for modified radical mastectomy. She had a huge thyroid mass on the anterior aspect of the neck (Figure 1). Neck computed tomography revealed tracheal deviation to the right, due to the external compression of the giant neck mass.

(Figure 2). Preoperative airway examination showed an adequate mouth opening with restricted neck extension and Mallampati 2. Due to the anticipated compromised airway informed consent was obtained for awake nasal fibreoptic intubation.

In the operation theatre all monitors were attached and a $16 \mathrm{G}$ venous access was taken on left hand. After adequate airway topicalization preoxygenation was done with $100 \%$ oxygen in head up position for $5 \mathrm{~min}$.

*Correspondence: Soumi Pathak

E mail:pathaksoumi@gmail.com

https://orcid.org/0000-0003-1987-6670

Received: 02/01/2018

Accepted:06/05/2018

DOI: http://doi.org/10.4038/slja.v26i2.8310

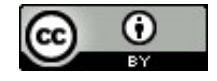

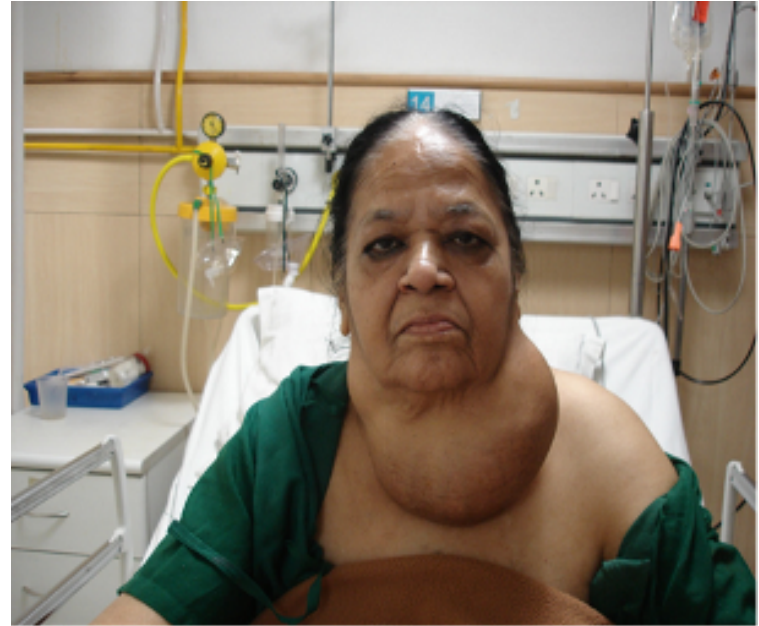

Figure 1 Large thyroid on the anterior aspect of neck

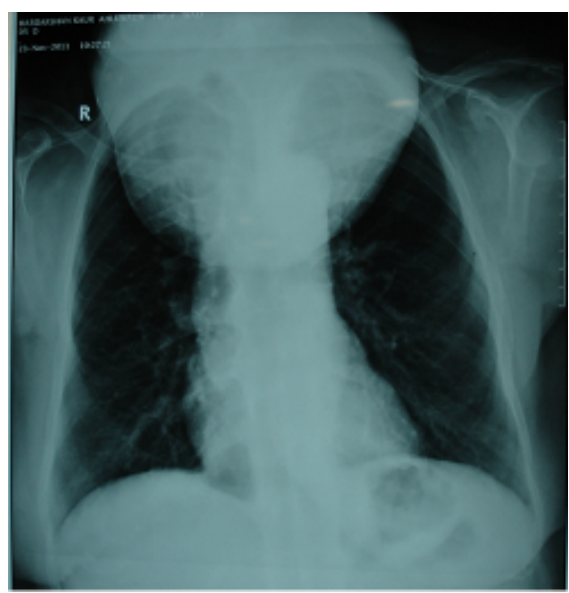

Figure 2 Chest $x$-ray

A $6.5 \mathrm{~mm}$ armoured endotracheal tube was inserted through her right nostril and a $3.6 \mathrm{~mm}$ Fibre scope Olympus LF-TP was introduced through the endotracheal tube. It revealed that the neck mass had distorted the laryngeal structures and had pushed the epiglottis posteriorly against the posterior pharyngeal wall, thus obscuring the laryngeal aperture and 
making the fibreoptic bronchoscope impossible to pass through the vocal cords. Occasionally, the flexible fiberscope could be passed through the vocal cords, but the endotracheal tube could not be negotiated, due to the grossly deviated trachea and the resistance of the collapsed laryngeal structure. Inhalation induction was done and a McCoy laryngoscope (Truphatek International Ltd, Netanya, Israel) was used to lever the collapsed larynx upward to create an extra space. This enabled us to probe the fibreoptic bronchoscope through the vocal cords and thereafter an endotracheal tube was railroaded into the trachea. The correct tracheal tube placement was confirmed by the fibreoptic bronchoscope. General anaesthesia was administered, and the rest of the perioperative period was uneventful. She was extubated after 12 hours on airway exchange catheter which was also eventually removed, and the patient was shifted to the ward on the next day.

\section{Case 2}

An 11-year-old female child presented with the complaint of a large submandibular mass of 1year duration which was associated with oral bleeding. On examination a large mass measuring $10 \times 8 \mathrm{~cm}$ was present in the oral cavity displacing the tongue to the right. (Figure 3)

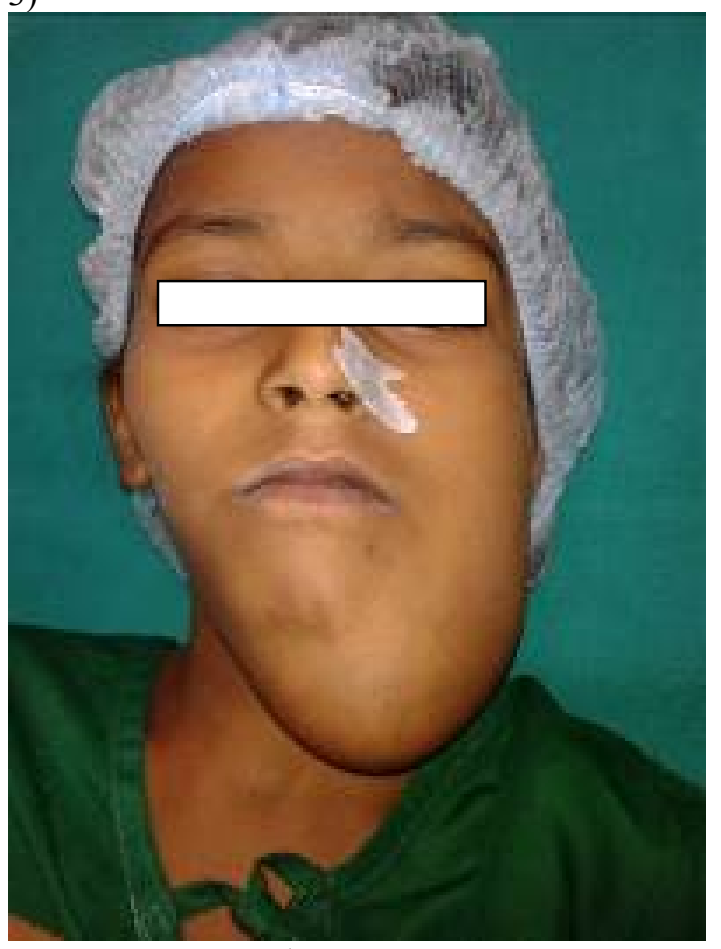

Figure 3 Large oral mass

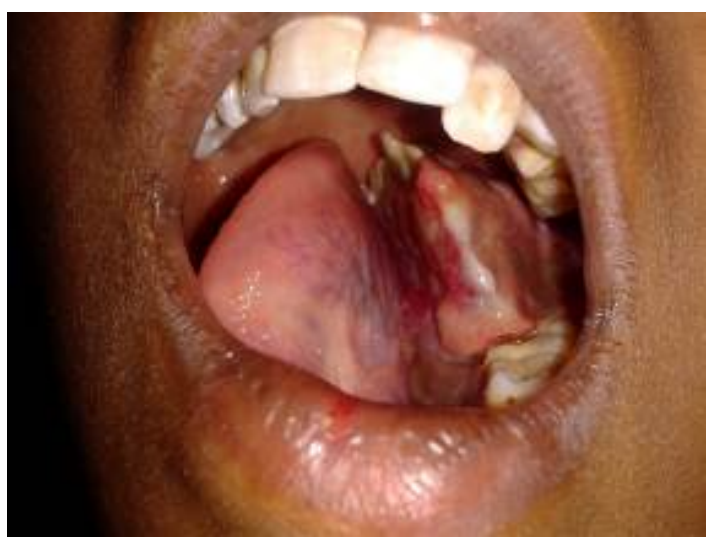

Figure 4 Mass in the oral cavity

Computed tomography revealed a mass extending into the parapharyngeal and submandibular space with marked luminal compromise of orophyranx and hypopharynx. All laboratory investigations were normal. Mallampati could not be assessed due to the mass. She was planned for left hemimandibulectomy with reconstruction with pectoralis major myocutaneous flap. After adequate premedication and informed consent for both fibreoptic intubation and tracheostomy, all standard monitors were applied, 18G intravenous access was taken after local infiltration. The child was nebulised with $2 \mathrm{ml}$ of $4 \%$ xylocaine. Inhalation induction was done. A $6.0 \mathrm{~mm}$ thermos softened endotracheal tube preloaded $3.6 \mathrm{~mm}$ fibreoptic bronchoscope was negotiated through the nasopharynx; however, the large oral mass and the presence of blood in the nasopharynx made vision impossible in spite of continuous suction. The child was turned to lateral position and gentle laryngoscopy was done with C Mac D blade. After suction, Magill forceps was used to guide the fibreoptic bronchoscope under vision through the vocal cords. Thereafter the endobronchial tube was railroaded into the glottis. Intraoperative period was uneventful. Due to the extensive surgery and anticipated prolonged intubation the child was tracheotomised at the end of surgery.

\section{Discussion}

Difficult tracheal intubation accounted for approximately $17 \%$ of adverse respiratory events for surgical patients ${ }^{1}$. Preparation involves careful planning; presence of experienced anaesthesiologists and difficult airway cart should be readily available. One should have multiple plans in case of failure of the initial 
airway plan. An informed consent for surgical airway in case of emergency must be taken.

Challenges of large neck mass ${ }^{2}$ are distorted airway, difficulties in visualizing the airway and risk of sudden complete airway occlusion. Although awake fibreoptic intubation is the gold standard for an anticipated difficult intubation ${ }^{3,4}$ the distorted airway anatomy or deviation of the larynx due to masses, oedema or soft tissue contraction can contribute to difficult fibreoptic exposures. BURP manoeuvre ${ }^{4}$ and assistant jaw thrust are recommended in facilitating fibreoptic bronchoscopy; however, in our patient the giant neck mass limited their use. Excessive force exerted during intubation may injure the glottic tissue or break the flexible bronchoscope.

In our first case after inhalation induction, McCoy laryngoscope was used to direct the bronchoscope. The McCoy laryngoscope has been designed to fulcrum its tilting blade tip within the pharynx and to concentrate the levering force on the spot of the vallecula, thus the epiglottis can be effectively lifted away from the posterior pharyngeal wall to expose the larynx further, even against the overlying tumour's compression. ${ }^{5,6}$

Our second case was a child with an oral vascular tumour. Awake or invasive procedures cannot be often applied to children because of there inadequate cooperation. Consequently, fibreoptic intubation under inhalational anaesthesia was planned. But the presence of blood and distorted anatomy due to the large oral mass made bronchoscopy intubation impossible. The lateral positioning helped as the tongue along with the mass got shifted to the right making space for the C MAC blade. We selected the Storz CMAC VL (Karl Storz, Tuttlingen, Germany) for the ability to continuously visualize the tip of the blade, reliably deliver surgical suction to the glottis to remove the trickling blood, and to railroad the endotracheal tube under vision.

\section{Conclusion}

Awake fibreoptic intubation can fail; thus, one should have an alternative plan for securing the airway without causing hypoxia. Thus, in cases where supraglottics airways are of limited use, Mc Coy laryngoscope and videolaryngoscope must be kept ready and one should be well versed with the technique to tackle the difficult airway scenario. Finally, after weighing the risk and benefits, decision to perform tracheostomy must be taken at the right time.

\section{References}

1. Caplan RA, Posner KL, Ward RJ, Cheney FW. Adverse respiratory events in anaesthesia: a closed claims analysis. Anaesthesiology 1990;72:828-33.

https://doi.org/10.1097/00000542-199005000$\underline{00010}$

2. Dabbagh A, Mobasseri N, Elyasi H, et al. A rapidly enlarging neck mass: the role of the sitting position in fiberoptic bronchoscopy for difficult intubation. Anesth Analg 2008;107:1627-9.

https://doi.org/10.1213/ane.0b013e318184f825 PMid:18931222

3. Ovassapian A. Fiberoptic endoscopy and the difficult airway. 2nd ed. Philadelphia: Lippincott-Raven Press; 1996. PMid:8695139

4. Vasudevan A, Venkat R, Badhe AS. Optimal external laryngeal manipulation versus McCoy blade in active position in patients with poor view of glottis on direct laryngoscopy. Indian J Anaesth 2010;54:45-8.

https://doi.org/10.4103/0019-5049.60497 PMid:20532072 PMCid:PMC2876900

5. Asai T, Shingu K. Difficulty in advancing a tracheal tube over a fibreoptic bronchoscope: incidence, causes and solutions. Br J Anaesth 2004;92:870-81.

https://doi.org/10.1093/bja/aeh136

PMid: 15121723

6. Aoyama K, Nagaoka E, Takenaka I, Kadoya T. The McCoy laryngoscope expands the laryngeal aperture in patients with difficult intubation. Anesthesiology 2000;92:1855-6. https://doi.org/10.1097/00000542-200006000$\underline{00068}$

PMid:10839953 